1 MicroRNA: master controllers of intracellular signalling pathways

2

Lui Pak-Yin ${ }^{1}$, Jin Dong-Yan ${ }^{1}$ and Stevenson Nigel John².

1 Department of Biochemistry, The University of Hong Kong, Pokfulam, Hong Kong, 2 School of Biochemistry and Immunology, Trinity Biomedical Sciences Institute, Trinity College Dublin, Dublin, Ireland.

\title{
Correspondence: N.stevenson@tcd.ie
} (1)

\section{Abstract} 3

Signaling pathways are essential intracellular networks that coordinate molecular outcomes to external stimuli. Tight regulation of these pathways is essential to ensure an appropriate response. microRNA (miRNA) is a class of small, non-coding RNA that regulates gene expression at a post-transcriptional level by binding to the complementary sequence on target mRNA, thus limiting protein translation. Intracellular pathways are controlled by protein regulators, such as Suppressor of Cytokine Signaling (SOCS) and A20. Until recently, expression of these classical protein regulators was thought to be controlled solely by transcriptional induction and proteasomal degradation; however, there is a growing body of evidence describing their regulation by miRNA. This new information has transformed our understanding of cell signaling by adding a Published in final edited form as:

Cell Mol Life Sci. 2015 Sep; 72(18):3531-42. doi: 10.1007/s00018-015-1940-0.

The final publication is available at link.springer.com 
25 previously unknown layer of regulatory control. This review outlines the miRNA

26 regulation of these classical protein regulators and describes their broad effects

27 at both cellular and disease levels. We review the regulation of three important

28 signaling pathways, including the JAK/STAT, NF- $\kappa$ B and TGF- $\beta$ pathways, and

29 summarize an extensive catalogue of their regulating miRNAs. This information

30 highlights that the importance of the miRNA regulon and reveals a previously

31 unknown regulatory landscape that must be included in the identification and

32 development of novel therapeutic targets for clinical disorders.

33

$34 \quad$ Keywords

35 microRNA; signal regulator; regulon; JAK-STAT; NF- $\kappa$ B; TGF- $\beta$

36

37 


\section{Introduction}

microRNA (miRNA) are a class of small, non-coding RNA of 19-25 nucleotides

41 (nt) in length that regulate gene expression at a post-transcriptional level by binding to the 3'UTR of the target transcript [1]. They are transcribed in the form of a primary transcript (pri-miRNA), either under the control of their own promoter regions or processed from a coding gene [2]. pri-miRNA are subsequently processed in the nucleus by RNase III-type endonuclease, Drosha, in association with an accessory double-stranded RNA (dsRNA)-binding protein, DiGeorge Critical Region 8 (DGCR8), into a stem-loop dsRNA pre-miRNA (or precursor miRNA), of 60-70nt in length, with a 2 nt overhang at the $3^{\prime}$ end $[3,4]$. This stem-loop dsRNA structure is transported from the nucleus to the cytoplasm by Exportin-5 [5, 6], where it is further processed by another RNase

51 III-type endonuclease, Dicer, and, in some cases, also with the help of accessory dsRNA-binding proteins, PACT and TRBP, into a mature dsRNA duplex of 19$21 \mathrm{nt}$ base pairs each side and a 2 nt overhang at each 3 ' end $[7,8]$. This duplex is then loaded onto an effector complex called RNA-induced silencing complex (RISC). One strand from the duplex acts as a guide to direct RISC in binding the target mRNA complementary sequence that mediates gene silencing [9] (Fig.1).

57 The discovery of microRNA in 1993 [10], revealed previously unknown layer of post-transcriptional control that revolutionized our concept of gene regulation. “Classical” protein regulators, such as SOCS and A20, are well known to quickly control signaling pathways through direct post-translational modification, such

61 as phosphorylation or ubiquitination, of their target protein. miRNAs do not Published in final edited form as:

Cell Mol Life Sci. 2015 Sep; 72(18):3531-42. doi: 10.1007/s00018-015-1940-0.

The final publication is available at link.springer.com 
regulate the activity of existing proteins, but rather limit the synthesis of new proteins, providing an extra layer of control that is now accepted as being an essential component of pathway regulation in processes such as cell development or differentiation $[11,12]$. However, as well as regulating key players within signaling pathways, miRNAs are increasingly being documented to regulate the "classical" regulators, thus providing additional control which we review in this manuscript. Here we describe this novel mechanism of molecular regulation of three major signaling pathways: Janus kinase/signal transducer and activator of transcription (JAK/STAT), nuclear factor kappa-light-chainenhancer of activated $\mathrm{B}$ cells $(\mathrm{NF}-\mathrm{\kappa B})$ and transforming growth factor beta (TGF $\beta$ ). We also outline how each miRNA plays a role in different cellular, ranging from normal growth and development, and clinical contexts, such as autoimmunity and cancer. In fact, this review clearly highlights that regulators of the cellular signaling pathways are important targets of regulation by miRNAs, and are significant targets for future research.

\section{JAK-STAT signaling pathway}

The JAK-STAT signaling pathway is mainly adopted by cytokine receptors to effect their anti-viral, inflammatory and cell proliferative activity [13]. Upon binding of extracellular ligands, such as interferon (IFN)- $\alpha / \beta$ and interleukin (IL)-6, to their respective dimerized transmembrane receptors, the preassociated JAK tyrosine kinases are brought into juxtaposition and activated by trans-autophosphorylation. Activated JAK kinases then mediate tyrosine 
phosphorylation on the conserved residue of the receptors, which causes the receptor recruitment of SH2-domain containing STAT proteins, which are in turn phosphorylated by JAKs, dissociate from the receptors, dimerize and translocate into the nucleus, where they act as transcriptional activators, driving expression of effector genes [14]. This pathway is central to the well being of our complex

91 immune system, with dysregulation leading to serious lymphoproliferative and autoimmune diseases [13], and is therefore under tight regulation at multiple levels [reviewed in 15].

\section{Regulation of SOCS by microRNAs}

The best studied regulators of the JAK-STAT pathway are suppressor of cytokine signaling (SOCS) proteins, which constitute a family of 8 members, including SOCS1-7 and cytokine-inducible Src homology 2 protein (CIS) [16]. SOCS proteins bind phosphorylated tyrosines of JAKs and/or the receptor via their

101 SH2-domains, thus blocking STAT recruitment [14]. Additionally, the SOCS box 102 domain recruits elongin B and C-containing ubiquitin E3 ligase complexes and 103 effectively mediates receptor degradation through the proteasome $[14,15]$. 104 Basal expression of SOCS is low, but can be up-regulated by cytokine stimulation, 105 providing an essential and effective negative feedback loop for the activated pathway [16]. Recent publications have documented that miRNA regulation of

107 SOCS expression is also key to optimal performance of the JAK/STAT pathway.

108 The role of miR-155 in regulating SOCS1 protein expression has been implicated 109 across a spectrum of cell types in nearly 20 publications. It was first described by Published in final edited form as:

Cell Mol Life Sci. 2015 Sep; 72(18):3531-42. doi: 10.1007/s00018-015-1940-0.

The final publication is available at link.springer.com 
110 Rudensky's group in the context of Foxp3 expression of regulatory T (Treg) cell

111 homeostasis. The authors noticed that an up-regulation of SOCS1 protein level 112 was detected in miR-155-deficient Treg cells, a phenotype which could be 113 reverted by the reintroduction of miR-155 [17]. Not limited to T cell biology, the 114 regulatory role of miR-155 on SOCS1 has also been implicated in NK cell 115 development and functions. In this study NK cells from miR-155 knockout mice 116 had elevated SOCS1 expression, and suffered from both impaired NK cell 117 generation and response to viral infection [18]. The functional consequences of 118 SOCS1 regulation by miR-155 are best illustrated by early work from Cao's group, 119 showing that even though miR-155 did not alter IFN expression in virally 120 infected macrophages, its suppression of SOCS1 levels increased STAT1 121 phosphorylation and downstream IFN stimulated gene (ISG) induction [19]. 122 Interestingly, the miR-155-SOCS1 relationship has also been actively implicated 123 in the field of cancer biology. An inverse correlation of miR-155 and SOCS1 124 expression was observed in breast cancer patients and cell lines, in which miR125155 conferred enhanced oncogenic properties [20]. In hepatocellular carcinoma 126 (HCC), miR-155 regulation of SOCS1 increases STAT3 signaling, in turn 127 stimulating matrix metalloproteinase (MMP)9 expression and increasing tumor 128 invasion [21]. Other miRNAs that have been shown to regulate SOCS1 expression 129 include miR-30d in prostate cancer [22], miR-122 in Huh-7 hepatocyte cells [23] 130 and miR-150 in lupus nephritis pathogenesis model [24]. The miR-19a/b family 131 was up-regulated in multiple myeloma (MM) and acted as an oncogenic 132 regulator via suppression of SOCS1, an important inhibitor of IL-6-mediated 133 growth in MM pathogenesis [25]. The miR-19a-SOCS1 relation has also been 
134 implicated in gastric cancer [26]. To our surprise, when we analyzed the

135 predicted targets of miR-19a within the JAK-STAT pathway by bioinformatics,

136 we discovered that the miR-19a target sequence is conserved between SOCS1

137 and SOCS3, and found that SOCS3 is a putative target of miR-19a and modulates

138 the activity of JAK-STAT signaling in response to IFN- $\alpha$ and IL-6 [27]. Together

139 these results demonstrate a realization of how evolution has "chosen" a single

140 miRNA species to regulate multiple cellular targets that converge onto the same

141 signaling pathway to exert an amplified combinatory effect on the pathway [12].

142 This broad effect of miR-19a provides the cellular machinery with a very

143 convenient switch to control the expression of a set of genes with powerful effect.

144 While miR-19a regulates multiple targets of the JAK-STAT pathway its regulation

145 also extends to the NF- $\mathrm{BB}$ signaling pathway [28]. Similarly, miR-155 inhibits

146 SOCS1 and SOCS3 expression, which enhances IFN production during persistent

147 viral infection, demonstrating its ability to also control several SOCSs that 148 regulate more than one pathway [29].

150 Targeting of SOCS by multiple miRNA also seems to be a common strategy 151 adopted by miRNA to regulate the JAK-STAT pathway. miR-203 was 152 demonstrated by two independent groups to regulate SOCS3 expression in 153 different cellular contexts. $\mathrm{Ru}$ and colleagues reported that miR-203 was up154 regulated in breast cancer and its knock-down correlated with enhanced level of 155 SOCS3 expression and improved chemosensitivity towards cisplatin [30]. Moffatt 156 and Lamont demonstrated that gingival epithelial cells infected with 157 Porphyromonas gingivalis had increased cellular miR-203 expression, resulting Published in final edited form as: 
in SOCS3 down-regulation and enhanced STAT3 activation [31]. On top of this, the latter showed that SOCS6 is also a putative target of miR-203 [31]. In another example, although miR-221 was implicated in regulating SOCS3 expression level, which conferred anti-tumorigenic effects in prostate cancer patients [32], TargetScan also predicts that SOCS1 and SOCS7 are additional targets for this miRNA [33], highlighting that our current knowledge and understanding of SOCS-targeting microRNAs is in its infancy and that future investigations may reveal an even more complex and intricate network of intracellular pathway regulation.

\section{Regulation of PIAS by microRNAs}

While JAK kinase- and receptor-mediated signaling are directly regulated by SOCSs, the downstream signaling protein, STAT, is regulated by protein inhibitor of activated STAT (PIAS), which effectively fine-tunes the pathway activity. The PIAS family in mammals is composed of 4 members: PIAS1, PIAS3, PIASx and PIASy, recognized to target STAT1, STAT3, STAT4 and STAT1, respectively [15]. Each member of the PIAS family contains a RING-finger-like zinc-binding domain (RLD), which confers small ubiquitin like modifier (SUMO) E3-ligase activity, thus mediating SUMOylation and consequential deactivation of STATs [34]. PIAS protein also regulates STAT independently of SUMOylation. Other mechanisms include direct blockage of STAT DNA binding and recruitment of co-repressors, such as histone deacetylase (HDAC) [reviewed in 34]. Although PIAS-STAT interaction is believed to be cytokine-dependent [34], the recent discovery of 
182

their regulation by miRNAs could be crucial in understanding the maintenance of the pathway integrity and cellular homeostasis.

Since PIAS3 negatively regulates STAT3, a key player in the IL-6-mediated ISG induction (driven by the IFN $-\gamma$ activated sequence [GAS]-containing promoter) [15], dysregulation of PIAS3 by miRNA could have devastating outcomes. Regulation of PIAS3 by miRNA was first proposed by Brock et al., who showed that miR-18a targeted the 3'UTR of PIAS3 mRNA, which suppressed its protein expression and resulted in IL-6-induced STAT3 activation in hepatocytes and triggered the acute-phase response [35]. Since the dysregulation of JAK-STAT signaling, via altered expression of SOCS by miRNA, is evident in many cancer models, it is no surprise to see it is equally true for PIAS. Indeed, regulation of PIAS3 by miR-18a has been implicated in gastric adenocarcinoma, in which a clinical correlation has been established between miR-18a, PIAS, JAK-STAT pathway activity and downstream anti-apoptotic and cell-proliferative genes [36]. Using proteomics PIAS3 was also identified as a cellular target of miR-21, which was highly expressed in MM [25], resulting in similar pathological outcomes to IL-6-induced JAK-STAT pathway activation [37]. PIAS3 is also a target for miR-125b in glioblastoma stem cells [38], further highlighting the multifaceted nature of its regulation and importance as a gatekeeper of oncogeneisis. Interestingly, microRNA regulation of PIAS3 even controls T cell development. In fact, inhibition of miR-301a expression in myelin auto-antigen exposed $\mathrm{CD}^{+} \mathrm{T}$ helper cells altered their cytokine expression profile and 
hampered their differentiation into Th17 cells, which was thought to be controlled by PIAS3 regulation of IL-6-STAT3 signaling [39].

207

Although there are 4 mammal PIAS proteins, evidence on their expression regulated by miRNA has only been reported for PIAS3. This exclusivity may be partly explained by the length of 3'UTR of their mRNA, since only human PIAS3

211 mRNA carries 3' UTR that spans for nearly 1000nt long, while the others are just 212 a few hundred. This speculation is supported by the study that some 213 housekeeping genes which have strong preference to minimize miRNA 214 regulation tend to evolve with a shorter 3' UTR, thus avoiding miRNA binding, 215 which consequently minimizes the risk of their accidental and undesirable 216 shutdown [40]. However, the physiological relevance of the PIAS's 3'UTR length

217 in regulating the JAK-STAT pathway warrants further investigation. In summary, 218 it is clear that the integrity of a functional JAK-STAT pathway is essential for 219 cellular homeostasis. Dysregulation of this signaling by miRNA may attribute to 220 many cancers and autoimmune diseases. However, it is important to remember 221 that there are other signaling pathways, such as the NF- $\kappa B$ and TGF $\beta$ cascades, 222 which also determine the outcome of effective cellular reactions and are now 223 known to be under the regulation of miRNAs.

NF-אB signaling pathway

227 NF- $\mathrm{B}$ mediates diverse biological processes at the cellular level, including 228 growth, development and inflammatory responses [41]. The canonical NF- $\mathrm{B}$ 
229 pathway mainly utilizes the RelA (also known as p65):p50 heterodimer as a

230 transcription factor to activate downstream target genes. In unstimulated cells

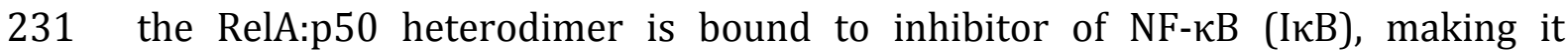

232 inaccessible to the nucleus and thus blocking gene transcription [42]. To remove

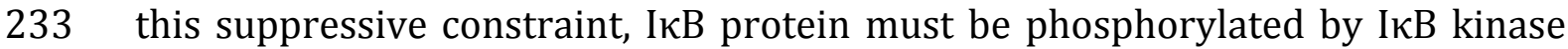

234 (IKK) complex, which constitutes two catalytic subunits, IKK $\alpha$ and IKK $\beta$, and one

235 regulatory subunit, NF-kB essential modulator (NEMO) (also known as IKK $\gamma$ ).

236 This initiates K48-polyubiquitination and subsequent proteosomal degradation

237 of IкB protein [41]. In the non-canonical (or alternative) NF- $\kappa B$ pathway, which

238 utilizes the RelB:p52 heterodimer, p100, the p52 predecessor, acts like I $\mathrm{B}$ to

239 suppress translocation and transcription activation of RelB when bound under

240 unstimulated conditions [42]. Upon activation, NF- $\kappa B$-inducing kinase (NIK),

241 with the help of IKK $\alpha$, induces phosphorylation of $\mathrm{p} 100$, which is then subjected

242 to ubiquitination and processing into p52, that, with RelB, serves as a

243 heterodimer transcription factor [reviewed in 43]. (Fig.2) Dysregulation of the

244 NF- $\mathrm{B}$ pathway accounts for many autoimmune, chronic inflammatory and

245 cancerous diseases [41], therefore, as with the JAK/STAT pathway, multiple

246 levels of regulation must be adopted to avoid disease [reviewed in 41].

248 Regulation of PP2A/C by microRNAs

250 Although the canonical and non-canonical pathways mobilize different cell

251 modulators, they are regulated using a similar mode of action: phosphorylation, 252 ubiquitination, and then proteosomal processing of the inhibitory binding 


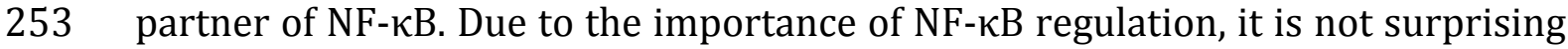

254 to see that some of these steps are also controlled by miRNA. In both pathways, $255 \mathrm{IKK} \alpha / \beta$ is the major protein kinase, engaging in the initial phosphorylation and 256 subsequent processing or degradation of the inhibitory binding partner [42]. In 257 order to become activated, IKK $\alpha / \beta$ complex requires trans-autophosphorylation 258 and phosphorylation from another upstream kinase, such as TGF- $\beta$ activated 259 kinase-1 (TAK1) or NIK. These phosphorylation sites are subjected to 260 dephosphorylation by a group of protein phosphatases called PP2A/C [44]. 261 Regulation of PP2A/C by miRNA is evident in cancer models. Two papers 262 recently reported that miR-520h targets $\mathrm{PP} 2 \mathrm{~A} / \mathrm{C}$ and promotes NF- $\mathrm{BB}-\mathrm{driven}$ 263 tumorigenic gene expression in breast cancer and ovarian cancer cell lines, as 264 well as in lung cancer patient samples $[45,46]$. The significance of regulating $265 \mathrm{PP} 2 \mathrm{~A} / \mathrm{C}$ is evident in the broad spectrum of miRNAs that control its expression, 266 including miR-1, miR-19, miR-31 and miR-133. While these miRNAs have not 267 been shown to impact the NF- $\mathrm{B}$ pathway in disease models, they will most 268 likely affect responses to the pathway and thus identify an area of research that 269 warrants investigation [47-49].

\section{Regulation of CYLD by microRNAs}

273 Ubiquitination of target proteins is arguably one of the most important and

274 influential molecular events within a cell and is thereby controlled by a series of 275 processes. Polyubiquitnation does not only enable IкB degradation or p100 processing, but is implicated throughout the NF- $\kappa \mathrm{B}$ pathway [reviewed in 50]. In 
277 the canonical pathway, NEMO undergoes K63-polyubiquitination in response to

278 TNF stimulation, which facilitates the recruitment of upstream activating factors 279 and, in turn, the activation of IKK complex [51]. To regulate IKK activation, the 280 tumor suppressor deubiquitinase, CYLD (cylindromatosis), removes 281 polyubiquitin chains from NEMO [42]. But the regulation of CYLD is now known 282 to involve miRNA, which has been shown to play an important role in cancer 283 pathogenesis. For example, miR-181b-1 was found to be up-regulated in an 284 oncogenic Src kinase transformed model and manipulation of cellular miR-181b2851 levels altered CYLD expression, NF- $\mathrm{BB}$ activity and mammary epithelial cell 286 line transformation [52]. The targeting of CYLD by miR-181b-1 was later 287 implicated in pancreatic cancer, in which increasing miR-181b-1 levels confer 288 cell line chemoresistance to gemcitabine, via the down-regulation of CYLD and 289 up-regulation of NF- $\kappa B$ activity [53]. In gastric cancer patients miR-362 was up290 regulated in tumor tissue samples, which inversely correlated to CYLD 291 expression, suggesting that miR-362 regulation of CYLD promoted NF- $\kappa B$ activity 292 and subsequently enhanced cell proliferation and apoptotic resistance [54]. In 293 addition, CYLD mRNA has been shown to be directly targeted by miR-182 and 294 miR-486, which promoted tumor aggressiveness of gliomas, again through NF$295 \kappa \mathrm{B}$ dysregulation $[55,56]$. The broad inhibitory remit of both these miRNAs is 296 clearly demonstrated in their spectrum of targets, with miR-486 also regulating 297 Cezanne (A20 family deubiquitinase) and A20-interacting partners, TNF- $\alpha$ 298 induced protein 3 (TNFAIP3) interacting protein (TNIP)1/2/3; and miR-182 299 regulating TNIP1, optineurin ubiquitin-binding protein (OPTN), and the 300 deubiquitinase ubiquitin-specific protease 15 (USP15) [55, 56]. 


\section{Regulation of A20 by microRNAs}

304 Another deubiquitination enzyme that has received much attention is A20 (also 305 known as TNFAIP3,). A20 contains an N-terminal ovarian tumor (OTU) 306 deubiquintation domain and a C-terminal zinc finger (ZnF) E3 ligase domain, 307 which are thought to have dual functions in K63-linked deubiquitination and 308 K48-linked polyubiquitination of substrates, such as receptor-interacting protein 309 (RIP)1 kinase [57]. RIP1 is an upstream activating kinase of TAK1, and its K63310 linked polyubiquitination is indispensible for IKK activation in the TNF-induced 311 NF- $\kappa B$ pathway [41]. Indeed, A20 mediates deubiquination of K63-linked 312 polyubiquitin chain on RIP1, but K48-linked polyubiquitination is actually 313 mediated by A20-binding partner, ITCH (also known as itchy E3 ubiquitin 314 protein ligase), which targets RIP1 for proteosomal degradation, thus 315 terminating the transduced signal [42]. (Fig.2) With its ability to negatively 316 regulate NF- $\kappa \mathrm{B}$ activity, $\mathrm{A} 20$ is regarded as a tumor suppressor and its 317 inactivation is frequently observed in various cancer models [57]. miRNA have 318 also been documented to manipulate A20 expression levels with obvious 319 consequences for NF- $\kappa \mathrm{B}$ activity in tumor cells.

321 Gantier and colleagues reported that global depletion of miRNA expression, 322 through conditional Dicer knock-out, impaired pro-inflammatory cytokine 323 induction [28]. Initially using TargetScan they predicted that negative regulators 324 of NF- $\kappa \mathrm{B}$, including A20 and other related proteins, such as its binding partners Published in final edited form as: Cell Mol Life Sci. 2015 Sep; 72(18):3531-42. doi: 10.1007/s00018-015-1940-0. The final publication is available at link.springer.com 
325 (Ring Finger Protein 11 (RNF11) and ITCH), A20 regulator (TNIP1) and other

326 deubiquitinases (CYLD and Cezanne), were targets of an oncogenic miRNA 327 cluster, miR-17-92 [28, 33]. Among the four miRNA families expressed in this 328 cluster, miR-19 was demonstrated to have a significant impact on NF- $\kappa \mathrm{B}$ activity 329 [28]. In this study, A20 and RNF11, as well as two other regulators of NF- $\mathrm{B}$ 330 (KDM2A and ZBTB16), were shown to be validated targets of miR-19, whereas 331 the suppressive effect on other predicted targets, including CYLD, was not 332 observed [28]. However, in T-cell acute lymphoblastic leukemia (T-ALL) patient 333 samples and cell lines, up-regulation of miR-19 inhibited CYLD expression, 334 leading to sustained NF- $\mathrm{B}$ activity [58], clearly demonstrating that miRNAs 335 regulate multiple targets from the same pathway in a cell- and disease-type 336 dependent fashion and highlighting the vast chasm of knowledge still to be 337 explored. In addition, apart from miR-19, miR-146a was also able to regulate the 338 expression of RNF11, which facilitated Hendra virus replication in NF- $\mathrm{BB}-$ 339 dependent manner [59]. miR-18a, from the miR-17-92 cluster, also reduced A20 340 in a model of rheumatoid arthritis (RA) and enhanced NF- $\kappa B$-dependent 341 expression of the matrix degrading enzyme, MMP1, and inflammatory cytokines, 342 such as IL-6, in synovial fibroblasts [60]. Similar establishment of NF- $\mathrm{BB}$ 343 dysregulation by miRNA-targeting of A20 was observed during Japanese 344 encephalitis virus infection. This virus induced cellular miR-29b expression, 345 which regulated A20 expression in a microglial cell line, thus enhancing NF- $\mathrm{KB}$ 346 activity [61]. In stark contrast, another miRNA from the same miR-29 family, 347 miR-29c, was found to be down-regulated in a Hepatitis B Virus (HBV)-related 348 HCC cell line and patient samples. This loss of miR-29 expression up-regulated Published in final edited form as: Cell Mol Life Sci. 2015 Sep; 72(18):3531-42. doi: 10.1007/s00018-015-1940-0. The final publication is available at link.springer.com 
A20 expression, resulting in restricted cell proliferation and enhanced apoptosis [62]. While miRNA are thought to predominately suppress target gene expression, in a sarcoma model, miR-29 bound the A20 3'UTR and prevented physical association of an RNA-binding protein $\mathrm{HuR}$, thus protecting A20 mRNA

353 from destabilization and degradation. In the same study, the authors showed that miR-125 could also regulate A20 expression [63], an observation mirrored in a macrophage polarization and diffuse large B-cell lymphoma model $[64,65]$.

In general, aberrant NF- $\mathrm{B}$ activity resulting from the dysregulation of its regulator by miRNA drives the expression of numerous pro-inflammatory cytokines and chemoattractants at the site of injury, and confers aggressiveness 360 and apoptotic tolerance to tumors at the cellular level. These events have been 361 evident in many of the aforementioned examples and believed to be the center of 362 many inflammatory diseases and cancers. Therefore, further elucidating the 363 control of NF- $\kappa \mathrm{B}$ regulators by miRNA will help us better understand the 364 development and progression of these diseases and reveal much needed 365 therapeutic targets.

\section{TGF $\beta$ signaling pathway}

369 From the beginning of life the TGF $\beta$ pathway is indispensable in coordinating cell

370 development and differentiation and is essential for sustaining a functioning

371 immune response [66]. The signal begins when functional, mature TGF $\beta$ is freed

372 by an endoprotease from a latent complex held within the extracellular matrix Published in final edited form as:

Cell Mol Life Sci. 2015 Sep; 72(18):3531-42. doi: 10.1007/s00018-015-1940-0.

The final publication is available at link.springer.com 
373 [67]. The binding of TGF $\beta$ to its cognate receptor complex, consisting of two

374 type-I receptors and two type-II receptors, triggers serine/threonine kinase activity on the type-II receptor molecule, which subsequently activates and phosphorylates the type-I receptor at its cytoplasmic domain [68]. Smad2 and

377 Smad3 (Receptor (R)-Smad proteins) are recruited to the phosphorylation site and themselves phosphorylated by the activated type-I receptor complex.

379 Phosphorylated Smad2/3 can then form a trimeric complex with other 380 coactivators, such as Smad4 and TIFI $\gamma$, to regulate gene expression in nucleus 381 [67]. Alternatively, the receptor complex can activate a Smad-independent 382 pathway through modulating Rho GTPase, MAP kinase and PI3K signaling 383 pathway activity, which regulates a different sets of target genes [66]. (Fig.2) To 384 achieve optimized signaling activity, the TGF $\beta$ signaling pathway output is tightly 385 regulated at different stages.

\section{Regulation of Smad7 by microRNAs}

While R-Smad proteins convey activating downstream signals, inhibitory Smad (I-Smad) proteins regulate this intracellular transduction. Smad7, for example, is 391 expressed in response to TGF $\beta$ pathway activation and provides efficient 392 negative feedback through several mechanisms [67]. It can physically bind to the type-I TGF $\beta$ receptor, acting as a direct competitor to R-Smad [67], or it can

394 further recruit other regulatory proteins, including PP1 phosphatase and the 395 Smad ubiquitin regulatory factor (Smurf) E3 ligase, which inactivate and 396 promote degradation of the receptor molecule, respectively $[67,68]$. We now Published in final edited form as:

Cell Mol Life Sci. 2015 Sep; 72(18):3531-42. doi: 10.1007/s00018-015-1940-0.

The final publication is available at link.springer.com 
know that expression of Smad7 is regulated by multiple miRNAs. The up-

398 regulation of miR-21 expression has been shown to suppress Smad7 expression

399 in HCV-infected liver biopsies. Interestingly, these findings correlated with

400 patient HCV load and fibrosis stage, indicating a role for miR-21 in accelerating

401 fibrogenesis [69]. Others observed that miR-21-mediated reduction of Smad7

402 correlated with expression of TGF $\beta$-induced fibrotic markers, such as alpha

403 smooth muscle actin ( $\alpha$-SMA) and fibronectin (Fn), which promoted epithelial-

404 mesenchymal transition (EMT) in lung fibrosis [70, 71], renal fibrosis [72, 73],

405 and systemic sclerosis [74, 75]. EMT also plays an important role in the 406 initiation of cancer metastasis. Complementary to this notion, miR-21 was up407 regulated in the invasive ductal carcinoma region of breast cancer and knock408 down of miR-21 restored Smad7 levels in a breast cancer cell line [76]. miR-21409 mediated reduction of Smad7 expression has also been implicated in the 410 generation of carcinoma-associated fibroblasts (CAFs), which confer

411 tumorigenesis, proliferation and invasiveness characteristics of tumors [77]. 412 However, elevated miR-21 levels are not always associated with enhanced 413 proliferation and differentiation. In the case of myelodysplastic syndromes 414 (characterized by ineffective hematopoiesis), suppression of Smad7 by miR-21 415 was found to decrease erythroid colony formation of CD34+ cells, while 416 inhibiting miR-21 could rescue red blood cell count and stimulate erythropoiesis 417 in transgenic mice [78]. As seen with miR-21, suppression of endogenous Smad7 418 is a common cancinogenic mechanism that promotes EMT. Other examples 419 include the miR-216a/217 cluster in HCC [79], miR-20a in gall bladder 420 carcinoma [80], miR-181a in ovarian cancer [81], and miR-106b-25 in breast Published in final edited form as: Cell Mol Life Sci. 2015 Sep; 72(18):3531-42. doi: 10.1007/s00018-015-1940-0. The final publication is available at link.springer.com 
421 cancer [82]. While the oncogenic role of these microRNAs has been described,

422 the tumor suppressive role of a selection has also been reported, with reduced

423 miR-25 in colon cancer [83] and miR-181c in metastatic neuroblastoma patients

424 [84]. Interestingly, both reports reasoned that the tumor suppressive roles of 425 miR-25 and miR-181c were accounted for by reduced Smad7 protein expression 426 and TGF $\beta$ activity, which would otherwise stimulate tumor growth and 427 migration $[83,84]$.

\section{Regulation of Smurf by microRNAs}

431 Reduced Smad7 expression in bronchial epithelial cells was also associated with 432 overexpressed miR-15b in a chronic obstructive pulmonary disease model [85]. 433 In their cell-based assays, the authors also found that, apart from Smad7, Smurf2 434 expression was affected by miR-15b [85]. Smurf proteins are E3 ubiquitin ligase 435 proteins, recruited by Smad7 to the type-I TGF $\beta$ receptor complex. Their 436 recruitment promotes proteosomal degradation of the receptor complex, thus 437 restricting signal transduction [86]. Antagonizing miR-322 and miR-503 action 438 on Smurf2 regulation was shown to inhibit the phosphorylation of Smad2 [87]. 439 As miRNA-suppression of Smad7 was observed in many cancers, it is not 440 surprising to see in an aggressive breast cancer model, Smurf2 was down441 regulated by miR-15, miR-16 and miR-128 [88]. miR-15b also targets Smurf1 442 during osteoblast differentiation, as a way to activate the expression of a master 443 transcription factor, Runx2 [89]. Smurf1 is also a target of miR-17 and miR-497; 
444 both of these studies showed reduced miRNA and up-regulated Smurf1

445 expression in periodontitis and metastatic ovarian cancer, respectively [90, 91].

\section{Regulation of GARP by microRNAs}

449 TGF $\beta$ is secreted and stored in the extracellular matrix inside a large latency 450 complex. The cytokine remains inactive and bound to the latency-associated 451 peptide until positive regulators increase the efficiency of its dissociation from 452 the large latency complex and it is processed into a mature form. Glycoprotein A 453 repetitions predominant protein (GARP), is expressed by $\mathrm{T}$ regulatory (Treg) 454 cells and tightly associated with the latency-associated peptide bound to 455 immature TGF $\beta$ [67]. GARP is essential for TGF $\beta$ activation [92], as it frees 456 immature TGF $\beta$ molecules from the latency complex [67]. miR-142-3p regulates 457 GARP expression and thus controls Treg cell proliferation [93]. Specifically, the 458 authors observed decreased expression of miR-142-3p in CD25+ CD4 T cells and 459 manipulation of miR-142-3p levels resulted in altered proliferation of these cells 460 [93], which is consistent with the concept of TGF $\beta$-mediated Treg cell

461 proliferation. No matter whether a miRNA is targeting the positive or negative 462 regulators of the TGF $\beta$ signaling pathway, any upset in the homeostatic balance 463 could lead to serious pathological consequences, like fibrosis or oncogenesis.

\section{Regulation of microRNA levels}


So far this review has discussed how miRNAs participate in signaling pathway regulation and provide an additional layer of supervision on pathway regulators, but, in order to fully understand how these "master regulators" control our signaling networks it is important to note how miRNAs themselves are regulated. Endogenous levels of miRNA are significantly linked to the final output of signalling pathways and are under the control of several factors. The majority of miRNAs is located in either intragenic or intergenic regions and is transcribed together with its host gene or from its own promoter [2]. The miR-106b-25 cluster is an example of intragenic miRNA, which sits itself within intron 13 of the miniature chromosome maintenance 7 (MCM7) gene [94]. This miRNA cluster encodes three miRNAs, namely miR-106b, miR-93, and miR-25, two of which, miR-106b and miR-25, we described above as regulators of Smad7. These miRNA were found to be frequently co-expressed and probably co-regulated with their host mRNA [95] and amplification of the MCM7 gene locus and its elevated expression with miR-106b-25 cluster have been associated with human malignancies $[94,96]$. The miR-17-92 cluster (also known as oncomir-1) is an example of intergenic miRNA that is expressed and processed from the C13orf25 transcript [96]. This miRNA cluster encodes six mature miRNAs, namely miR-17, miR-18a, miR-19a, miR-20a, miR-19b-1, and miR-92-1, which have broad effects on multiple pathway regulators, including SOCS, PIAS, A20, Smad7 and Smurf1.

It is interesting to note that the expression of both MCM7/miR-106b-25 and miR-17-92 genes are induced by common transcription factors, E2F1 and MYC [96]. E2F1 and MYC are involved in a positive feedback loop making both 
491 proteins capable of regulating one another [97]. The entire regulatory network may be further complicated by the negative regulation of E2F1 expression by miR-106b and miR-20a [96]. These constitute an important regulatory mechanism that allows these miRNAs to be expressed at optimized level. It is

495 foreseeable that in the event of sub-optimal miRNA levels, the negative feedback constrain is lenient, so the positive feedback loop of the transcription factors encourages the expression of these miRNAs. Alternative, when miRNA expression becomes excessive, it places a heavy negative feedback constrain on

499 the transcription factors, so that the continuous expression of miRNA can be 500 eventually shut off. Therefore, it is evident that the sequence of molecular events 501 responsible for miRNA expression can be more complex than their simple 502 regulation of target genes and networks, and hence should be analysed case by 503 case. In fact, when considering the mechanisms that alter the steady-state level 504 of any miRNA, we should also take into account the cell type, its half-life and 505 transient intracellular turnover [reviewed in 98].

Insights derived from regulator-targeting miRNAs

509 Although the role played by each miRNA appears to be context-dependent in 510 individual studies, some have collectively demonstrated its versatility in 511 regulating multiple regulators of a signaling pathway. Examples include miR-15 512 (targeting Smad7, Smurf1 and Smurf2 in TGF $\beta$ pathway) [85, 88, 89], miR-19 513 (targeting SOCS1 and SOCS3 in JAK-STAT pathway; A20, CYLD and RNF11 in NF514 кB pathway) [25-28, 58], miR-155 (targeting SOCS1 and SOCS3 in JAK-STAT Published in final edited form as: Cell Mol Life Sci. 2015 Sep; 72(18):3531-42. doi: 10.1007/s00018-015-1940-0. The final publication is available at link.springer.com 
pathway) [29], miR-203 (targeting SOCS3 and SOCS6 in JAK-STAT pathway) [30, 31]. This versatility is indeed conferred by the ability of miRNA to regulate gene expression at translation level by binding to and targeting the complementary sequence present on 3' UTR of any gene, irrespective of their actual protein coding sequence, such that multiple genes that share similar gene function and acquire the same complementary sequence can be regulated simultaneously by a common miRNA. The miRNA-target relationship is now thought to be under tight natural selection and is believed to have co-evolved with one another, as well as the whole regulatory network [99].

To date, vast majority of publications have focused on the validation of a single gene targeted by miRNA that has implications in different biological models. While this has been limited by both our lack of knowledge and experimental capabilities, it has certainly led to an under-estimation of miRNA capacity in modulating the entire regulatory network as a "master regulon". Fortunately, the recent advancement in next-generation sequencing and other molecular biological techniques, such as photoactivatable-ribonucleoside-enhanced crosslinking and immunoprecipitation (PAR-CLIP), have already improved our understanding and knowledge in the transcriptome-wide regulation of miRNA in many cellular contexts. Bioinformatic database analysis remains a cornerstone for the predictive analysis of miRNAs and their targets and will continue to be used to understand how miRNA can act beyond a single gene to regulate an entire network [100]. Careful data-mining procedures and the use of a systems biology approach will conserve efforts from validating all of the predicted targets 
and focusing on the pathway predicted to be affected by the specific miRNA and

540 the corresponding regulators involved. Additionally, when regarding the

541 timeframe and strength of miRNA regulation, our current knowledge is greatly

542 limited by the use of existing non-physiological methodology that manipulates

543 endogenous miRNA expression in cell-based systems. Furthermore, it is

544 important to note, that in most cases, owing to direct gene amplification of the

545 miRNA region or altered expression of the transcription factors responsible for

546 regulating miRNA expression, miRNAs levels during disease pathogenesis are

547 aberrantly expressed [96].

549 The plethora of current evidence outlined in this review identifies miRNAs as

550 "master controllers" of intracellular signaling pathways in many disease models

551 and in the era of new therapies against miRNA, this evidence highlights them as 552 powerful targets for therapeutic development with highly significant clinical 553 applications. In many of the studies covered in this review, manipulation of 554 endogenous miRNA levels by chemically synthesized analog or inhibitor could 555 revert the phenotype caused by the dysregulated miRNA, and therefore provide 556 the proof-of-principle for potential drug development. While therapeutic

557 development, from "bench to bedside" is a long, arduous and expensive process,

558 recent advances with the development of the first miRNA-targeting drug, 559 miravirsen, (miR-122 targeting locked-nucleic acid (LNA)-modified inhibitor for 560 treatment of hepatitis C virus infection, currently in phase 2 clinical trial), have 561 brought the entire miRNA research community closer to therapeutic solutions 562 than ever before [101]. Another miRNA-based drug, MRX34, is the first miRNA 
563 mimic for miR-34 and has entered phase 1 trial for treatment of HCC [102].

564 These outstanding advances demonstrate that miRNA are promising targets for 565 therapeutic intervention and with our advanced understanding of their 566 regulation of different cellular pathways and disease pathogenesis, it is expected 567 more pre-clinically validated drugs will enter clinical trials and be used in our 568 actual daily clinical practice.

\section{Conclusion}

This article has reviewed how miRNAs potently act as novel regulators of 573 classically known inhibitors of the JAK-STAT, NF- $\kappa B$ and TGF $\beta$ signaling 574 pathways. We now have a much deeper understanding of the way in which 575 miRNAs regulate many pathological diseases and normal developmental 576 processes. More importantly, we have identified a reiterating concept, whereby 577 miRNAs bind 3'UTRs of their target irrespective of the protein coding sequence, 578 and regulate multiple targets, which usually work at different levels of the 579 signaling cascade, within the same signaling pathway. This allows miRNA to 580 provide another layer of signaling regulation, in order to achieve maximal effect 581 and avoid detrimental responses to stimuli. With this concept in mind, it is 582 essential for future research of miRNA-target identification to consider the 583 regulation network (or regulon) of specific miRNA, in order to achieve total 584 understanding of the mechanism of any cellular process. More advanced 585 techniques can reveal the transcriptome-wide regulation of miRNAs should be 586 considered a standard and essential approach. This not only takes the concept of Published in final edited form as: Cell Mol Life Sci. 2015 Sep; 72(18):3531-42. doi: 10.1007/s00018-015-1940-0. The final publication is available at link.springer.com 
a single miRNA regulating different targets within the same pathway into

588 account, but also provides a bigger picture how miRNA can regulate different targets among different signaling pathways.

590

\section{References}

592

1. P. D. Zamore, B. Haley, Ribo-gnome: the big world of small RNAs. Science 309, 1519-1524 (2005).

595

2. D. P. Bartel, MicroRNAs: genomics, biogenesis, mechanism, and function. Cell 116, 281-297 (2004).

3. Y. Lee, C. Ahn, J. Han, H. Choi, J. Kim, J. Yim, J. Lee, P. Provost, O. Radmark, S.

600 Kim, V. N. Kim, The nuclear RNase III Drosha initiates microRNA processing.

$601 \quad$ Nature 425, 415-419 (2003).

602

603

4. J. Han, Y. Lee, K. H. Yeom, Y. K. Kim, H. Jin, V. N. Kim, The Drosha-DGCR8

604 complex in primary microRNA processing. Genes Dev. 18, 3016-3027 (2004).

605

606

5. C. Gwizdek, B. Ossareh-Nazari, A. M. Brownawell, A. Doglio, E. Bertrand, I. G.

607 Macara, C. Dargemont, Exportin-5 mediates nuclear export of minihelix-

608 containing RNAs. J. Biol. Chem. 278, 5505-5508 (2003). 
610 6. R. Yi, Y. Qin, I.G. Macara, B. R. Cullen, Exportin-5 mediates the nuclear export of

611 pre-microRNAs and short hairpin RNAs. Genes Dev. 17, 3011-3016 (2003).

613 7. R. F. Ketting, S. E. Fischer, E. Bernstein, T. Sijen, G. J. Hannon, R. H. Plasterk,

614 Dicer functions in RNA interference and in synthesis of small RNA involved in

615 developmental timing in C. elegans. Genes Dev. 15, 2654-2659 (2001).

616

617 8. K. H. Kok, M. H. Ng, Y. P. Ching, D. Y. Jin, Human TRBP and PACT directly

618 interact with each other and associate with dicer to facilitate the production of

619 small interfering RNA. J. Biol. Chem. 282, 17649-17657 (2007).

620

621 9. S. L. Ameres, J. Martinez, R. Schroeder, Molecular basis for target RNA

622 recognition and cleavage by human RISC. Cell 130, 101-112 (2007).

623

624 10. R. C. Lee, R. L. Feinbaum, V. Ambros, The C. elegans heterochronic gene lin-4 625 encodes small RNAs with antisense complementarity to lin-14. Cell 75, 843-854 626 (1993).

627

628 11. G. Hutvagner, J. McLachlan, A. E. Pasquinelli, E. Balint, T. Tuschl, P. D. Zamore, 629 A cellular function for the RNA-interference enzyme Dicer in the maturation of 630 the let-7 small temporal RNA. Science 293, 834-838 (2001).

632 12. M. Inui, G. Martello, S. Piccolo, MicroRNA control of signal transduction. Nat.

633 Rev. Mol. Cell Biol. 11, 252-263 (2010).

Published in final edited form as:

Cell Mol Life Sci. 2015 Sep; 72(18):3531-42. doi: 10.1007/s00018-015-1940-0.

The final publication is available at link.springer.com 
635 13. J .J. O’Shea, R. Plenge, JAK and STAT signaling molecules in immunoregulation 636 and immune-mediated disease. Immunity 36, 542-550 (2012).

638 14. W. M. Schneider, M. D. Chevillotte, C. M. Rice, Interferon-stimulated genes: a complex web of host defenses. Annu. Rev. Immunol. 32, 513-545 (2014).

640

15. K. Shuai, B. Liu, Regulation of JAK-STAT signalling in the immune system. Nat. 642 Rev. Immunol. 3, 900-911 (2003).

643

644 16. B. A. Croker, H. Kiu, S. E. Nicholson, SOCS regulation of the JAK/STAT

645 signalling pathway. Sem. Cell Dev. Biol. 19, 414-422 (2008).

646

647 17. L. F. Lu, T. H. Thai, D. P. Calado, A. Chaudhry, M. Kubo, K. Tanaka, G. B. Loeb,

648 H. Lee, A. Yoshimura, K. Rajewsky, A. Y. Rudensky, Foxp3-dependent

649 microRNA155 confers competitive fitness to regulatory T cells by targeting

650 SOCS1 protein. Immunity 30, 80-91 (2009).

651

652 18. C. L. Zawislak, A. M. Beaulieu, G.B. Loeb, J. Karo, D. Canner, N. A. Bezman, L. L.

653 Lanier, A. Y. Rudensky, J. C. Sun, Stage-specific regulation of natural killer cell

654 homeostasis and response against viral infection by microRNA-155. Proc. Natl.

655 Acad. Sci. U.S.A. 110, 6967-6972 (2013).

656

Published in final edited form as:

Cell Mol Life Sci. 2015 Sep; 72(18):3531-42. doi: 10.1007/s00018-015-1940-0.

The final publication is available at link.springer.com 
19. P. Wang, J. Hou, L. Lin, C. Wang, X. Liu, D. Li, F. Ma, Z. Wang, X. Cao, Inducible microRNA-155 feedback promotes type I IFN signaling in antiviral innate immunity by targeting suppressor of cytokine signaling 1. J. Immunol. 185, 6226-6233 (2010).

20. S. Jiang, H. W. Zhang, M. H. Lu, X. H. He, Y. Li, H. Gu, M. F. Liu, E. D. Wang, MicroRNA-155 functions as an OncomiR in breast cancer by targeting the suppressor of cytokine signaling 1 gene. Cancer Res. 70, 3119-3127 (2010).

21. X. L. Yan, Y. L. Jia, L. Chen, Q. Zeng, J. N. Zhou, C. J. Fu, H. X. Chen, H. F. Yuan, Z. W. Li, L. Shi, Y. C. Xu, J. X. Wang, X. M. Zhang, L. J. He, C. Zhai, W. Yue, X. T. Pei, Hepatocellular carcinoma-associated mesenchymal stem cells promote hepatocarcinoma progression: role of the S100A4-miR155-SOCS1-MMP9 axis. Hepatology 57, 2274-2286 (2013).

22. N. Kobayashi, H. Uemura, K. Nagahama, K. Okudela, M. Furuya, Y. Ino, Y. Ito, H. Hirano, Y. Inayama, I. Aoki, Y. Nagashima, Y. Kubota, H. Ishiguro, Identification of miR-30d as a novel prognostic maker of prostate cancer. Oncotarget 3, 1455$1471(2012)$.

\section{A. Li, W. Song, J. Qian, Y. Li, J. He, Q. Zhang, W. Li, A. Zhai, W. Kao, Y. Hu, H. Li, J.} Wu, H. Ling, Z. Zhong, F. Zhang, MiR-122 modulates type I interferon expression through blocking suppressor of cytokine signaling 1. Int. J. Biochem. Cell Biol. 45, 858-865 (2013). 
24. H. Zhou, S. A. Hasni, P. Perez, M. Tandon, S.I. Jang, C. Zheng, J. B. Kopp, H. 3rd nephritis by downregulating SOCS1. J. Am. Soc. Nephrol. 24, 1073-1087 (2013).

685

686

25. F. Pichiorri, S. S. Suh, M. Ladetto, M. Kuehl, T. Palumbo, D. Drandi, C. Taccioli, 12890 (2008).

691

27. A. S. Collins, C. E. McCoy, A. T. Lloyd, C. O'Farrelly, N. J. Stevenson, miR-19a: an effective regulator of SOCS3 and enhancer of JAK-STAT signalling. PLoS One 8, e69090 (2013).

699

28. M. P. Gantier, H. J. Stunden, C. E. McCoy, M. A. Behlke, D. Wang, M. KaparakisLiaskos, S. T. Sarvestani, Y. H. Yang, D. Xu, S. C. Corr, E. F. Morand, B. R. Williams, (2012). 
29. A. Zhai, J. Qian, W. Kao, A. Li, Y. Li, J. He, Q. Zhang, W. Song, Y. Fu, J. Wu, X. Chen, H. Li, Z. Zhong, H. Ling, F. Zhang, Borna disease virus encoded phosphoprotein inhibits host innate immunity by regulating miR-155. Antiviral Res. 98, 66-75 (2013).

30. P. Ru, R. Steele, E. C. Hsueh, R. B. Ray, Anti-miR-203 Upregulates SOCS3

Expression in Breast Cancer Cells and Enhances Cisplatin Chemosensitivity. Genes Cancer 2, 720-727 (2011).

31. C. E. Moffatt, R. J. Lamont, Porphyromonas gingivalis induction of microRNA203 expression controls suppressor of cytokine signaling 3 in gingival epithelial cells. Infect Immun. 79, 2632-2637 (2011).

32. B. Kneitz, M. Krebs, C. Kalogirou, M. Schubert, S. Joniau, H. van Poppel, E. Lerut, S. Kneitz, C. J. Scholz, P. Ströbel, M. Gessler, H. Riedmiller, M. Spahn, Survival in Patients with High-Risk Prostate Cancer Is Predicted by miR-221, Which Regulates Proliferation, Apoptosis, and Invasion of Prostate Cancer Cells by Inhibiting IRF2 and SOCS3. Cancer Res. 74, 2591-2603 (2014).

33. B. P. Lewis, C. B. Burge, D. P. Bartel, Conserved seed pairing, often flanked by adenosines, indicates that thousands of human genes are microRNA targets. Cell $120,15-20$ (2005). 
34. K. Shuai, B. Liu, Regulation of gene-activation pathways by PIAS proteins in the immune system. Nat. Rev. Immunol. 5, 593-605 (2005).

35. M. Brock, M. Trenkmann, R. E. Gay, S. Gay, R. Speich, L. C. Huber, MicroRNA18a enhances the interleukin-6-mediated production of the acute-phase proteins fibrinogen and haptoglobin in human hepatocytes. J. Biol. Chem. 286, 4014240150 (2011).

36. W. Wu, M. Takanashi, N. Borjigin, S. I. Ohno, K. Fujita, S. Hoshino, Y. Osaka, A. Tsuchida, M. Kuroda, MicroRNA-18a modulates STAT3 activity through negative regulation of PIAS3 during gastric adenocarcinogenesis. Br. J. Cancer 108, 653661 (2013).

\section{Q. Xiong, Q. Zhong, J. Zhang, M. Yang, C. Li, P. Zheng, L. J. Bi, F. Ge,} Identification of novel miR-21 target proteins in multiple myeloma cells by quantitative proteomics. J. Proteome Res. 11, 2078-2090 (2012).

\section{L. Shi, Y. Wan, G. Sun, S. Zhang, Z. Wang, Y. Zeng, miR-125b inhibitor may} enhance the invasion-prevention activity of temozolomide in glioblastoma stem cells by targeting PIAS3. BioDrugs 28, 41-54 (2014).

39. M. P. Mycko, M. Cichalewska, A. Machlanska, H. Cwiklinska, M. Mariasiewicz, K. W. Selmaj, MicroRNA-301a regulation of a T-helper 17 immune response 
751 controls autoimmune demyelination. Proc. Natl. Acad. Sci. U.S.A. 109, E1248-

7521257 (2012).

753

754

40. A. Stark, J. Brennecke, N. Bushati, R. B. Russell, S. M. Cohen, Animal

MicroRNAs confer robustness to gene expression and have a significant impact on 3'UTR evolution. Cell 123, 1133-1146 (2005).

757

758

41. J. Napetschnig, H. Wu, Molecular basis of NF-кB signaling. Annu. Rev. Biophys.

42, 443-468 (2013).

760

761

42. S. Vallabhapurapu, M. Karin, Regulation and function of NF-kappaB

762

transcription factors in the immune system. Annu. Rev. Immunol. 27, 693-733

763 (2009).

764

765

43. S. C. Sun, Non-canonical NF-кB signaling pathway. Cell Res. 21, 71-85 (2011).

766 344-362 (2008).

45. J. L. Su, P. B. Chen, Y. H. Chen, S. C. Chen, Y. W. Chang, Y. H. Jan, X. Cheng, M. 
46. Y. H. Yu, H. A. Chen, P. S. Chen, Y. J. Cheng, W. H. Hsu, Y. W. Chang, Y. H. Chen, Y. Jan, M. Hsiao, T. Y. Chang, Y. H. Liu, Y. M. Jeng, C. H. Wu, M. T. Huang, Y. H. Su, M. C. Hung, M. H. Chien, C. Y. Chen, M. L. Kuo, J. L. Su, MiR-520h-mediated FOXC2 regulation is critical for inhibition of lung cancer progression by resveratrol. Oncogene 32, 431-443 (2013).

\section{X. Liu, L. F. Sempere, H. Ouyang, V. A. Memoli, A. S. Andrew, Y. Luo, E.}

Demidenko, M. Korc, W. Shi, M. Preis, K. H. Dragnev, H. Li, J. Direnzo, M. Bak, S. J.

Freemantle, S. Kauppinen, E. Dmitrovsky, MicroRNA-31 functions as an oncogenic microRNA in mouse and human lung cancer cells by repressing specific tumor suppressors. J Clin. Invest. 120, 1298-1309 (2010).

48. K. J. Mavrakis, A. L. Wolfe, E. Oricchio, T. Palomero, K. de Keersmaecker, K. McJunkin, J. Zuber, T. James, A. A. Khan, C. S. Leslie, J. S. Parker, P. J. Paddison, W. Tam, A. Ferrando, H. G. Wendel, Genome-wide RNA-mediated interference screen identifies miR-19 targets in Notch-induced T-cell acute lymphoblastic leukaemia. Nat. Cell Biol. 12, 372-379 (2010).

49. A. E. Belevych, S. E. Sansom, R. Terentyeva, H. T. Ho, Y. Nishijima, M. M. Martin, H. K. Jindal, J. A. Rochira, Y. Kunitomo, M. Abdellatif, C. A. Carnes, T. S. Elton, S. Györke, D. Terentyev, MicroRNA-1 and -133 increase arrhythmogenesis in heart failure by dissociating phosphatase activity from RyR2 complex. PLoS One 6, e28324 (2011).

\section{Published in final edited form as:}

Cell Mol Life Sci. 2015 Sep; 72(18):3531-42. doi: 10.1007/s00018-015-1940-0.

The final publication is available at link.springer.com 
50. J. Chen, Z. J. Chen, Regulation of NF- $\kappa B$ by ubiquitination. Curr. Opin. Immunol.

799

800

801

802

803

804

805

806

807

808

809

810

811

812

813

814

815

816

817

818

819

820

821

25, 4-12 (2013).

51. H. Sebban, S. Yamaoka, G. Courtois, Posttranslational modifications of NEMO and its partners in NF-kappaB signaling. Trends Cell Biol. 16, 569-577 (2006).

52. D. Iliopoulos, S. A. Jaeger, H. A. Hirsch, M. L. Bulyk, K. Struhl, STAT3 activation of miR-21 and miR-181b-1 via PTEN and CYLD are part of the epigenetic switch linking inflammation to cancer. Mol. Cell 39, 493-506 (2010).

53. D. Takiuchi, H. Eguchi, H. Nagano, Y. Iwagami, Y. Tomimaru, H. Wada, K.

Kawamoto, S. Kobayashi, S. Marubashi, M. Tanemura, M. Mori, Y. Doki, Involvement of microRNA-181b in the gemcitabine resistance of pancreatic cancer cells. Pancreatology 13, 517-523 (2013).

54. J. T. Xia, L. Z. Chen, W. H. Jian, K. B. Wang, Y. Z. Yang, W. L. He, Y. L. He, D. Chen, W. Li, MicroRNA-362 induces cell proliferation and apoptosis resistance in gastric cancer by activation of NF-кB signaling. J. Transl. Med. 12, 33 (2014).

55. L. Song, L. Liu, Z. Wu, Y. Li, Z. Ying, C. Lin, J. Wu, B. Hu, S. Y. Cheng, M. Li, J. Li, TGF- $\beta$ induces miR-182 to sustain NF-kB activation in glioma subsets. J. Clin. Invest. 122, 3563-3578 (2012).

Published in final edited form as:

Cell Mol Life Sci. 2015 Sep; 72(18):3531-42. doi: 10.1007/s00018-015-1940-0.

The final publication is available at link.springer.com 
822

823

824

825

826

827

828

829

830

831

832

833

834

835

836

837

838

839

840

841

842

843

844

56. L. Song, C. Lin, H. Gong, C. Wang, L. Liu, J. Wu, S. Tao, B. Hu, S. Y. Cheng, M. Li, J. Li, miR-486 sustains NF- $\kappa$ B activity by disrupting multiple NF- $\kappa$-negative feedback loops. Cell Res. 23, 274-289 (2013).

57. S. G. Hymowitz, I. E. Wertz, A20: from ubiquitin editing to tumour suppression. Nat. Rev. Cancer 10, 332-341 (2010).

58. H. Ye, X. Liu, M. Lv, Y. Wu, S. Kuang, J. Gong, P. Yuan, Z. Zhong, Q. Li, H. Jia, J.

Sun, Z. Chen, A. Y. Guo, MicroRNA and transcription factor co-regulatory network analysis reveals miR-19 inhibits CYLD in T-cell acute lymphoblastic leukemia. Nucleic Acids Res. 40, 5201-5214 (2012).

59. C. R. Stewart, G. A. Marsh, K. A. Jenkins, M. P. Gantier, M. L. Tizard, D.

Middleton, J. W. Lowenthal, J. Haining, L. Izzard, T. J. Gough, C. Deffrasnes, J.

Stambas, R. Robinson, H. G. Heine, J. A. Pallister, A. J. Foord, A. G. Bean, L. F. Wang, Promotion of Hendra virus replication by microRNA 146a. J. Virol. 87, 3782-3791 (2013).

60. M. Trenkmann, M. Brock, R. E. Gay, B. A. Michel, S. Gay, L. C. Huber, Tumor necrosis factor $\alpha$-induced microRNA-18a activates rheumatoid arthritis synovial fibroblasts through a feedback loop in NF-кB signaling. Arthritis Rheum. 65, 916927 (2013). 
845 Proc. Natl. Acad. Sci. U.S.A. 109, 7865-7870 (2012). 586-592 (2011). A20 mRNA from degradation by HuR. Sci. Signal. 6, ra63 (2013). 287, 21816-21825 (2012).

61. M. C. Thounaojam, D. K. Kaushik, K. Kundu, A. Basu, MicroRNA-29b modulates Japanese encephalitis virus-induced microglia activation by targeting tumor necrosis factor alpha-induced protein 3. J. Neurochem. 129, 143-154 (2014).

62. C. M. Wang, Y. Wang, C. G. Fan, F. F. Xu, W. S. Sun, Y. G. Liu, J. H. Jia, miR-29c targets TNFAIP3, inhibits cell proliferation and induces apoptosis in hepatitis B virus-related hepatocellular carcinoma. Biochem. Biophys. Res. Commun. 411,

63. M. Y. Balkhi, O. H. Iwenofu, N. Bakkar, K. J. Ladner, D. S. Chandler, P. J.

Houghton, C. A. London, W. Kraybill, D. Perrotti, C. M. Croce, C. Keller, D. C.

Guttridge, miR-29 acts as a decoy in sarcomas to protect the tumor suppressor

64. J. W. Graff, A. M. Dickson, G. Clay, A. P. McCaffrey, M. E. Wilson, Identifying functional microRNAs in macrophages with polarized phenotypes. J. Biol. Chem.

65. S. W. Kim, K. Ramasamy, H. Bouamar, A. P. Lin, D. Jiang, R. C. Aguiar, MicroRNAs miR-125a and miR-125b constitutively activate the NF- $\kappa B$ pathway by targeting the tumor necrosis factor alpha-induced protein 3 (TNFAIP3, A20). 
66. A. Weiss, L. Attisano, The TGFbeta superfamily signaling pathway. Wiley

Interdiscip. Rev. Dev. Biol. 2, 47-63 (2013).

67. M. A. Travis, D. Sheppard, TGF- $\beta$ activation and function in immunity. Annu.

Rev. Immunol. 32, 51-82 (2014).

874

875

68. J. Massagué, TGF $\beta$ signalling in context. Nat. Rev. Mol. Cell Biol. 13, 616-630

877 (2012).

878

879

69. R. T. Marquez, S. Bandyopadhyay, E. B. Wendlandt, K. Keck, B. A. Hoffer, M. S.

880

Icardi, R. N. Christensen, W. N. Schmidt, A. P. McCaffrey, Correlation between

881 microRNA expression levels and clinical parameters associated with chronic

882 hepatitis C viral infection in humans. Lab. Invest. 90, 1727-1736 (2010).

883

884

70. G. Liu, A. Friggeri, Y. Yang, J. Milosevic, Q. Ding, V. J. Thannickal, N. Kaminski, E. 885 Abraham, miR-21 mediates fibrogenic activation of pulmonary fibroblasts and

886 lung fibrosis. J. Exp. Med. 207, 1589-1597 (2010).

887

888 71. M. Yamada, H. Kubo, C. Ota, T. Takahashi, Y. Tando, T. Suzuki, N. Fujino, T.

889 Makiguchi, K. Takagi, T. Suzuki, M. Ichinose, The increase of microRNA-21 during

890 lung fibrosis and its contribution to epithelial-mesenchymal transition in

891 pulmonary epithelial cells. Respir. Res. 14, 95 (2013).

892

Published in final edited form as:

Cell Mol Life Sci. 2015 Sep; 72(18):3531-42. doi: 10.1007/s00018-015-1940-0.

The final publication is available at link.springer.com 
893

894

895

896

897

898

899

900

901

902

903

904

905

906

907

908

909

910

911

912

913

914

72. J. Y. Wang, Y. B. Gao, N. Zhang, D. W. Zou, P. Wang, Z. Y. Zhu, J. Y. Li, S. N. Zhou, S. C. Wang, Y. Y. Wang, J. K. Yang, miR-21 overexpression enhances TGF- $\beta 1$ induced epithelial-to-mesenchymal transition by target smad7 and aggravates renal damage in diabetic nephropathy. Mol. Cell Endocrinol. 392,163-172 (2014).

73. X. Zhong, A. C. Chung, H. Y. Chen, Y. Dong, X. M. Meng, R. Li, W. Yang, F. F. Hou, H. Y. Lan, miR-21 is a key therapeutic target for renal injury in a mouse model of type 2 diabetes. Diabetologia 56, 663-674 (2013).

74. H. Zhu, Y. Li, S. Qu, H. Luo, Y. Zhou, Y. Wang, H. Zhao, Y. You, X. Xiao, X. Zuo, MicroRNA expression abnormalities in limited cutaneous scleroderma and diffuse cutaneous scleroderma. J. Clin. Immunol. 32, 514-522 (2012).

75. H. Zhu, H. Luo, Y. Li, Y. Zhou, Y. Jiang, J. Chai, X. Xiao, Y. You, X. Zuo, MicroRNA21 in scleroderma fibrosis and its function in TGF- $\beta$-regulated fibrosis-related genes expression. J. Clin. Immunol. 33, 1100-1109 (2013).

76. L. Chen, Y. Li, Y. Fu, J. Peng, M. H. Mo, M. Stamatakos, C. B. Teal, R. F. Brem, A. Stojadinovic, M. Grinkemeyer, T. A. McCaffrey, Y. G. Man, S. W. Fu, Role of deregulated microRNAs in breast cancer progression using FFPE tissue. PLoS One 8, e54213 (2013).

Published in final edited form as:

Cell Mol Life Sci. 2015 Sep; 72(18):3531-42. doi: 10.1007/s00018-015-1940-0.

The final publication is available at link.springer.com 
915

916

917

918

919

920

921

922

923

924

925

926

927

928

929

930

931

932

933

934

935

936

937

938

77. Q. Li, D. Zhang, Y. Wang, P. Sun, X. Hou, J. Larner, W. Xiong, J. Mi, MiR-

21/Smad 7 signaling determines TGF- $\beta 1$-induced CAF formation. Sci. Rep. 3, 2038 (2013).

78. T. D. Bhagat, L. Zhou, L. Sokol, R. Kessel, G. Caceres, K. Gundabolu, R. Tamari, S. Gordon, I. Mantzaris, T. Jodlowski, Y. Yu, X. Jing, R. Polineni, K. Bhatia, A.

Pellagatti, J. Boultwood, S. Kambhampati, U. Steidl, C. Stein, W. Ju, G. Liu, P. Kenny, A. List, M. Bitzer, A. Verma, miR-21 mediates hematopoietic suppression in MDS by activating TGF- $\beta$ signaling. Blood 121, 2875-2881 (2013).

79. H. Xia, L. L. Ooi, K. M. Hui, MicroRNA-216a/217-induced epithelialmesenchymal transition targets PTEN and SMAD7 to promote drug resistance and recurrence of liver cancer. Hepatology 58, 629-641 (2013).

80. Y. Chang, C. Liu, J. Yang, G. Liu, F. Feng, J. Tang, L. Hu, L. Li, F. Jiang, C. Chen, R. Wang, Y. Yang, X. Jiang, M. Wu, L. Chen, H. Wang, MiR-20a triggers metastasis of gallbladder carcinoma. J. Hepatol. 59, 518-527 (2013).

81. A. Parikh, C. Lee, J. Peronne, S. Marchini, A. Baccarini, V. Kolev, C. Romualdi, R. Fruscio, H. Shah, F. Wang, G. Mullokandov, D. Fishman, M. D'Incalci, J. Rahaman, T. Kalir, R. W. Redline, B. D. Brown, G. Narla, A. DiFeo, microRNA-181a has a critical role in ovarian cancer progression through the regulation of the epithelialmesenchymal transition. Nat. Commun. 5, 2977 (2014).

Published in final edited form as:

Cell Mol Life Sci. 2015 Sep; 72(18):3531-42. doi: 10.1007/s00018-015-1940-0.

The final publication is available at link.springer.com 
82. A. L. Smith, R. Iwanaga, D. J. Drasin, D. S. Micalizzi, R. L. Vartuli, A. C. Tan, H. L.

940 Ford, The miR-106b-25 cluster targets Smad7, activates TGF- $\beta$ signaling, and

941 induces EMT and tumor initiating cell characteristics downstream of Six1 in

942 human breast cancer. Oncogene 31, 5162-5171 (2012).

943

944 83. Q. Li, C. Zou, C. Zou, Z. Han, H. Xiao, H. Wei, W. Wang, L. Zhang, X. Zhang, Q.

945 Tang, C. Zhang, J. Tao, X. Wang, X. Gao, MicroRNA-25 functions as a potential

946 tumor suppressor in colon cancer by targeting Smad7. Cancer Lett. 335, 168-174

947 (2013).

948

84. Y. Li, H. Wang, J. Li, W. Yue, MiR-181c modulates the proliferation, migration,

950 and invasion of neuroblastoma cells by targeting Smad7. Acta. Biochim. Biophys.

951 Sin. (Shanghai) 46, 48-55 (2014).

952

953

85. M. E. Ezzie, M. Crawford, J. H. Cho, R. Orellana, S. Zhang, R. Gelinas, K. Batte, L.

86. D. David, S. A. Nair, M. R. Pillai, Smurf E3 ubiquitin ligases at the cross roads

958 of oncogenesis and tumor suppression. Biochim. Biophys. Acta. 1835, 119-128

959 (2013).

960

961 87. S. Cao, L. Xiao, J. N. Rao, T. Zou, L. Liu, D. Zhang, D. J. Turner, M. Gorospe, J. Y.

962 Wang, Inhibition of Smurf2 translation by miR-322/503 modulates TGF- 
$\beta /$ Smad2 signaling and intestinal epithelial homeostasis. Mol. Biol. Cell 25, 1234-

9641243 (2014).

965

966

88. X. Liu, X. Gu, L. Sun, A. B. Flowers, A. W. Rademaker, Y. Zhou, H. Kiyokawa,

Downregulation of Smurf2, a tumor-suppressive ubiquitin ligase, in triple-

968

negative breast cancers: involvement of the RB-microRNA axis. BMC Cancer 14,

969

57 (2014).

970

971

89. S. Vimalraj, N. C. Partridge, N. Selvamurugan, A Positive Role of MicroRNA-

972

15b on Regulation of Osteoblast Differentiation. J. Cell. Physiol. 229, 1236-1244

973

(2014).

974

975

90. Y. Liu, W. Liu, C. Hu, Z. Xue, G. Wang, B. Ding, H. Luo, L. Tang, X. Kong, X. Chen,

976

N. Liu, Y. Ding, Y. Jin, MiR-17 modulates osteogenic differentiation through a

977

coherent feed-forward loop in mesenchymal stem cells isolated from periodontal

978 ligaments of patients with periodontitis. Stem Cells 29, 1804-1816 (2011).

979

980

91. W. Wang, F. Ren, Q. Wu, D. Jiang, H. Li, Z. Peng, J. Wang, H. Shi, MicroRNA-497

981 inhibition of ovarian cancer cell migration and invasion through targeting of

982 SMAD specific E3 ubiquitin protein ligase 1. Biochem. Biophys. Res. Commun. 449, $983 \quad 432-437$ (2014).

984

985 92. J. P. Edwards, H. Fujii, A. X. Zhou, J. Creemers, D. Unutmaz, E. M. Shevach,

986 Regulation of the expression of GARP/latent TGF- $\beta 1$ complexes on mouse T cells

Published in final edited form as:

Cell Mol Life Sci. 2015 Sep; 72(18):3531-42. doi: 10.1007/s00018-015-1940-0.

The final publication is available at link.springer.com 
and their role in regulatory T cell and Th17 differentiation. J. Immunol. 190,

988 5506-5515 (2013).

989

990

93. Q. Zhou, S. Haupt, I. Prots, K. Thümmler, E. Kremmer, P. E. Lipsky, H. Schulze-

Koops, A. Skapenko, miR-142-3p is involved in CD25+ CD4 T cell proliferation by

992

targeting the expression of glycoprotein A repetitions predominant. J. Immunol.

993

190, 6579-6588 (2013).

994

995

94. J.-H. Luo. Oncogenic activity of MCM7 transforming cluster. World J. Clin Oncol.

996

2, 120-124 (2011).

997

95. S. Baskerville, D. P. Bartel, Microarray profiling of microRNAs reveals

frequent coexpression with neighboring miRNAs and host genes. $R N A$ 11, 241-

1000 247 (2005).

1001

1002

96. F. Petrocca, A. Vecchione, Emerging Role of miR-106b-25/miR-17-92 Clusters

1003 in the Control of Transforming Growth Factor $\beta$ Signaling. Cancer Res $\mathbf{6 8}, \mathbf{8 1 9 1 -}$

1004 8194 (2008).

1005

97. I. Matsumura, H. Tanaka, Y. Kanakura, E2F1 and c-Myc in cell growth and 1007 death. Cell Cycle 2, 333-338 (2003).

98. Z. Zhang, Y.-W. Qin, G. Brewer, Q. Jing, MicroRNA degradation and turnover:

1010 regulating the regulators. Wiley Interdiscip. Rev. RNA 3, 593-600 (2012).

Published in final edited form as:

Cell Mol Life Sci. 2015 Sep; 72(18):3531-42. doi: 10.1007/s00018-015-1940-0.

The final publication is available at link.springer.com 
1012 99. E. Berezikov, Evolution of microRNA diversity and regulation in animals

1013 Nature Rev. Genetics 12, 846-860 (2011).

1014

1015 100. C. Backes, E. Meese, H.-P. Lenhof, A. Keller, A dictionary on microRNAs and

1016 their putative target pathways. Nucl. Acids Res. 38, 4476-4486 (2010).

1017

1018 101. M. Lindow, S. Kauppinen, Discovering the first microRNA-targeted drug. J.

1019 Cell Biol. 199, 407-412 (2012).

1020

1021 102. A. Bouchie, First microRNA mimic enters clinic. Nature Biotechnology 31, 1022577 (2013). 


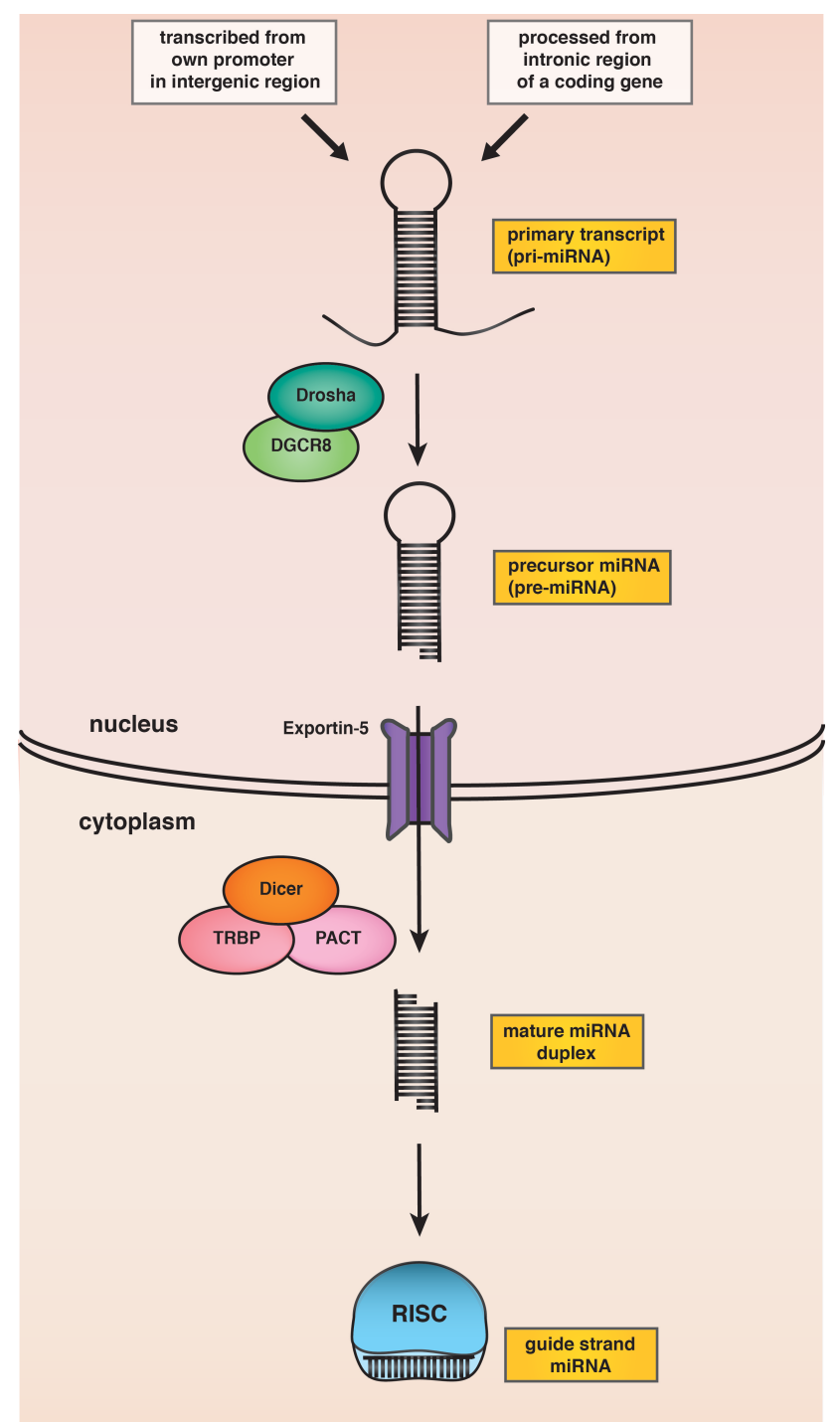

1025 Fig.1 Biogenesis of microRNA. In the nucleus, miRNA is either transcribed from its own promoter in intergenic region or processed from the intronic region of a

1027 coding gene as a primary transcript (pri-miRNA). It is processed by an RNase III1028 type endonuclease family protein Drosha, with an accessory dsRNA-binding 1029 protein DGCR8, into a precursor molecule (pre-miRNA) with stem-loop structure 1030 of around 60-70nt in length and a 2nt overhang at the 3' end. It is then exported 1031 to the cytoplasm by a transport protein Exportin-5. In the cytoplasm, pre-miRNA 1032 is further processed by another RNase III-type endonuclease family protein 1033 Dicer, in some cases also with the help of accessory dsRNA-binding proteins Published in final edited form as:

Cell Mol Life Sci. 2015 Sep; 72(18):3531-42. doi: 10.1007/s00018-015-1940-0.

The final publication is available at link.springer.com 
1034 PACT and TRBP, into a dsRNA duplex of 19-21nt base pair region and a 2 nt 1035 overhang at each 3' end. One of the two strand (guide strand) from this miRNA 1036 duplex is loaded onto RISC complex to effect its gene silencing function. 


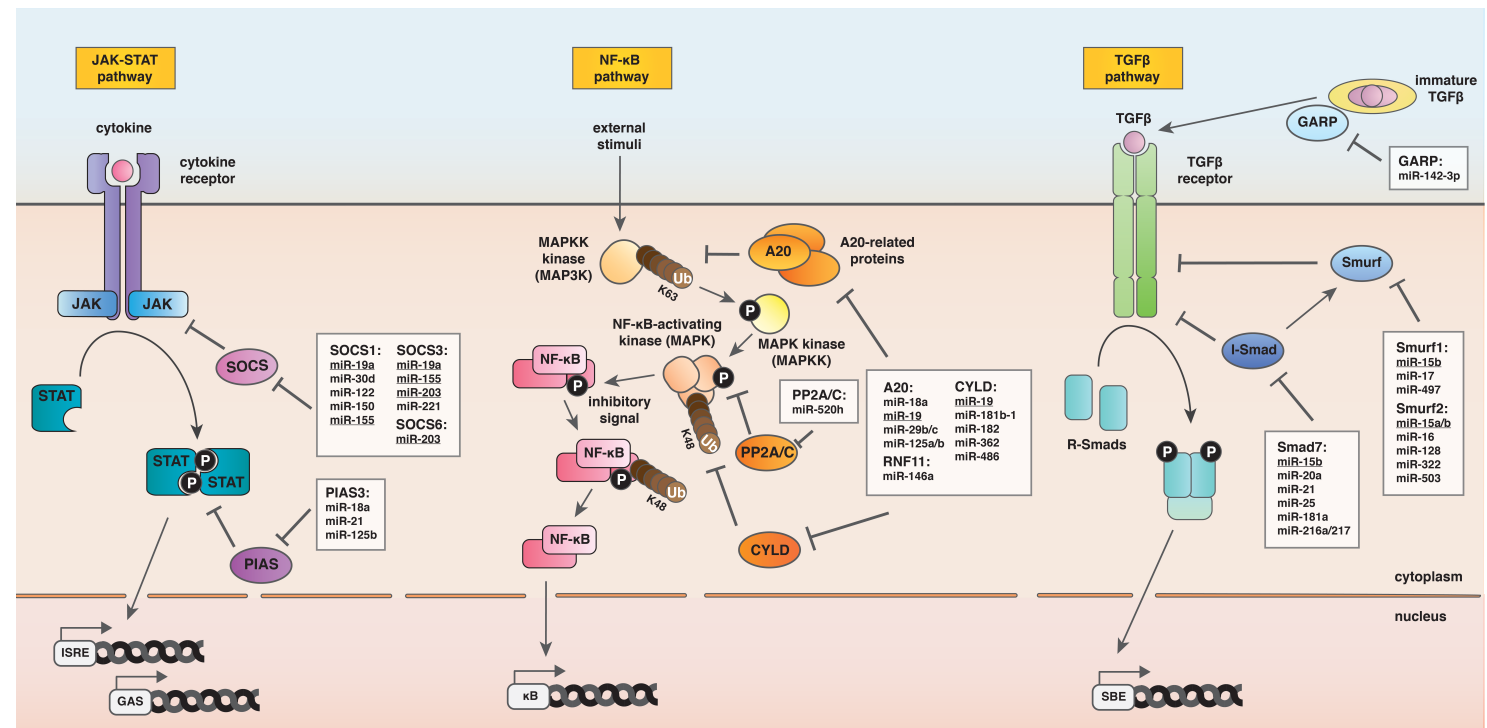

Fig.2 Regulation of key regulators of cellular pathways by miRNAs. Left: JAK-

1040 STAT pathway. Binding of cytokine to its cognate receptor pair activates and

1041 phosphorylates receptor-associated JAK kinase which then phosphorylates

1042 downstream transcription factor STATs. Activated STATs dimerize and expose

1043 nuclear localization signal to enter nucleus and promote transcription from

1044 promoter carrying interferon-stimulated responsive element (ISRE) or IFN- $\gamma$

1045 activated sequence (GAS). SOCS proteins negatively regulate JAK kinase by

1046 blocking the binding with STATs and promoting the degradation of cytokine

1047 receptors; and PIAS proteins negatively regulate STAT transcription factors by

1048 blocking its binding to DNA and recruiting corepressor to inhibit transcription.

1049 Both SOCS and PIAS are under tight regulation by miRNAs. Middle: NF- $\kappa B$

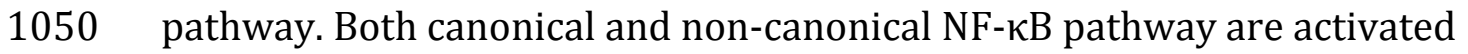

1051 through similar mechanism. Under unstimulated condition, the activity of NF- $\mathrm{B}$

1052 is suppressed by an inhibitory signal (canonical: inhibitor of $\kappa \mathrm{B}(\mathrm{I} \kappa \mathrm{B})$; non-

1053 canonical: ankyrin repeats on p100). To remove this inhibitory constrain, the

Published in final edited form as:

Cell Mol Life Sci. 2015 Sep; 72(18):3531-42. doi: 10.1007/s00018-015-1940-0.

The final publication is available at link.springer.com 
1054 inhibitory signal needs to be labeled by K48-polyubiquitin chain and targeted to 1055 proteosomal processing. Prior to K48-polyubiquitination by E3 ligase, the target 1056 protein must be phosphorylated by an NF-kB-activating kinase, also known as 1057 mitogen-activating protein kinase (MAPK) (for example, canonical: IкB kinase 1058 (IKK); non-canonical: NF-кB-inducing kinase (NIK). In order to become activated 1059 to mediate downstream phosphorylation event, MAPK needs to be 1060 phosphorylated by an upstream kinase, also known as MAPK kinase (MAPKK) 1061 (for example TGF $\beta$ activated kinase-1 (TAK1)). This activating phosphorylation 1062 can be removed by protein phosphatase PP2A/C. Like MAPK, activation of 1063 MAPKK requires the phosphorylation of another upstream kinase, also known as 1064 MAPKK kinase (MAP3K). MAP3K can be activated by K63-polyubiquitination in 1065 response to external stimuli. In terms of tumor necrosis factor (TNF) stimulation, 1066 the MAP3K protein, receptor-interacting protein (RIP)1 kinase, can be 1067 deactivated by deubiquitinase A20, as well as other A20-related proteins, 1068 including its binding partner Ring Finger Protein 11 (RNF11) as well as another 1069 deubiquitinase CYLD, by removing its K63-polyubiquitin chain and recruiting E3 1070 ligase to tag a K48-polyubiquitin chain to promote its degradation. All these 1071 regulators, A20, RNF11, CYLD, and PP2A/C, can be regulated by miRNAs. Right: 1072 TGF $\beta$ pathway. Binding of TGF $\beta$ to its cognate receptors phosphorylates and 1073 activates receptor Smad (R-Smad) proteins, such as Smad2 and 3. R-Smad 1074 proteins bind other coactivator and translocate into nucleus to drive 1075 transcription from promoter with Smad-binding element (SBE). Activation of R1076 Smad proteins can be inhibited by inhibitory Smad (I-Smad) such as Smad7 1077 through direct blockage of receptor and recruitment of other deactivating 
1078 enzymes such as Smad ubiquitin regulatory factor (Smurf) E3 ligase. TGF $\beta$ is

1079 normally secreted in a closed immature form into the extracellular matrix.

1080 Glycoprotein A repetitions predominant protein (GARP) expressed by T

1081 regulatory (Treg) cells can facilitate the maturation of TGF $\beta$, thus acting as a

1082 positive regulator of the pathway. I-Smad, Smurf and GARP can be regulated by

1083 miRNAs. miRNAs that can regulate multiple cellular targets from the same

1084 signaling pathway are underlined. 